\title{
Soft tissue and cellular preservation in vertebrate skeletal elements from the Cretaceous to the present
}

\author{
Mary Higby Schweitzer ${ }^{1,2, *}$, Jennifer L. Wittmeyer ${ }^{1}$ and John R. Horner ${ }^{3}$ \\ ${ }^{1}$ Department of Marine, Earth and Atmospheric Sciences, North Carolina State University, Raleigh, NC 27695, USA \\ ${ }^{2}$ North Carolina Museum of Natural Science, 11 W. Jones Street, Raleigh, NC 27601, USA \\ ${ }^{3}$ Museum of the Rockies, Montana State University, Bozeman, MT 59717, USA
}

\begin{abstract}
Soft tissues and cell-like microstructures derived from skeletal elements of a well-preserved Tyrannosaurus rex (MOR 1125) were represented by four components in fragments of demineralized cortical and/or medullary bone: flexible and fibrous bone matrix; transparent, hollow and pliable blood vessels; intravascular material, including in some cases, structures morphologically reminiscent of vertebrate red blood cells; and osteocytes with intracellular contents and flexible filipodia. The present study attempts to trace the occurrence of these four components in bone from specimens spanning multiple geological time periods and varied depositional environments. At least three of the four components persist in some skeletal elements of specimens dating to the Campanian. Fibrous bone matrix is more altered over time in morphology and less likely to persist than vessels and/or osteocytes. Vessels vary greatly in preservation, even within the same specimen, with some regions retaining pliability and other regions almost crystalline. Osteocytes also vary, with some retaining long filipodia and transparency, while others present with short and stubby filipodia and deeply pigmented nuclei, or are pigmented throughout with no nucleus visible. Alternative hypotheses are considered to explain the origin/source of observed materials. Finally, a twopart mechanism, involving first cross-linking of molecular components and subsequent mineralization, is proposed to explain the surprising presence of still-soft elements in fossil bone. These results suggest that present models of fossilization processes may be incomplete and that soft tissue elements may be more commonly preserved, even in older specimens, than previously thought. Additionally, in many cases, osteocytes with defined nuclei are preserved, and may represent an important source for informative molecular data.
\end{abstract}

Keywords: dinosaur; soft tissues; red blood cells; osteocytes; vessels; preservation

\section{INTRODUCTION}

The presence of soft tissues and apparent cells in $68 \mathrm{Ma}$ dinosaur bone (Schweitzer et al. 2005a) was unexpected, particularly because these components retain both morphological and some functional characteristics of their original state. Models have been proposed to account for the preservation of non-biomineralized tissues, organic matter and kerogens in the fossil record (Butterfield 1990; Stankiewicz et al. 2000; Nguyen \& Harvey 2001; Briggs 2003; Butterfield 2003). However, these taphonomic, molecular or biogeochemical models do not explain the detailed preservation of still-soft, transparent, hollow and flexible tissues and cells over geological time, given that natural processes such as decay and degradation (Behrensmeyer \& Kidwell 1985; Briggs et al. 1993; Denys 2002; Wilson \& Pollard 2002; Jans et al. 2004; Prieto et al. 2004), cellular apoptosis or necrosis (e.g. Usui et al. 1989; Briggs et al. 2000; Vass et al. 2002) and chemical and/or enzymatic degradation (Lindahl 1993; Riley \& Collins 1994; Collins et al. 2000, 2002) act in concert to rapidly degrade both the molecules and the tissues they comprise.

\footnotetext{
* Author for correspondence (schweitzer@ncsu.edu).
}

Electronic supplementary material is available at http://dx.doi.org/10 1098/rspb.2006.3705 or via http://www.journals.royalsoc.ac.uk.
Therefore, one focus of subsequent research has been to conduct a sampling across taxa and environments to begin to determine the extent and distribution of such preservation, to identify potential environmental links or predictors and to propose a chemical mechanism that builds upon previously proposed taphonomic models (e.g. Briggs 2003; Butterfield 2003; and references therein; MacNamera et al. 2006) to explain exceptional morphological preservation.

The possibility that original molecules or fragments of molecules may be preserved in fossil remains exhibiting exceptional morphological preservation has also been addressed (e.g. DeJong et al. 1974; Collins et al. 1991, 1995, 1999; Schweitzer et al. 1997b, 1999a,b; Gotherstrom et al. 2002; Smith et al. 2005 and many others). Analyses to test this possibility are beyond the scope of this paper, which simply seeks to document the occurrence of soft tissues in fossils through time.

\section{SPECIMEN DESCRIPTION AND METHODS}

The specimens used in this study range in age from immediately post-mortem to Triassic (approx. $210 \mathrm{Ma}$ ) and derive from multiple environments, different continents and varied taxa, as provided by cooperating colleagues and institutions. Some yielded all four 
components (soft fibrous matrix, hollow vessels, osteocytes and intravascular contents, including some with celllike morphology), and some, few or none of these. For methods, see Appendix A in the electronic supplementary material. For the description of additional specimens not presented in the main text, see table 1 and Appendix B in the electronic supplementary material.

\section{RESULTS}

With the exception of MOR 91.72 (12 ka mammoth, altered matrix only), specimens younger than Pleistocene (approx. 100-300 kyr) did not differ significantly at the morphological level from 'fresh' bone, presenting with all four soft tissue components (matrix, vessels and both cell types). Demineralized matrix was more flexible and less resistant to deformation in moa, bison and mammoth (MOR 91.72) than in ostrich and emu.

Chicken, ostrich, emu, moa and bison required digestion with collagenase, in addition to demineralization to liberate vessels and cells. All materials less than $1 \mathrm{Ma}$, including the Pleistocene mammoth (Mammuthus columbi, MOR 604; Hill \& Schweitzer 1999; Schweitzer et al. 2002) and American mastodon (Mammut americanum, MOR 605; Hill 1998) responded to collagenase digestion with visible changes to the organic matrix (table 1). However, in many cases of both fossil and extant samples, a small remnant of flexible, fibrous 'matrix' did not digest, but remained associated with vessels. This undigested material is referred to as 'sheet'. While demineralization of some Cretaceous fossils yielded soft fibrous matrix, it was visibly unaffected by subsequent collagenase digestion (table 1) and may have features in common with this sheet material. It is unknown if this sheet material corresponds to the matrix in any specimen. Chemical and molecular characterization is underway and will be reported separately.

Study specimens yielding at least three of the four soft tissue components are detailed later and figured in the main text. Descriptions follow table 1, beginning with most recent specimens, and continuing to oldest. Ostrich data are combined from one recent and one older specimen for brevity and space. Specimens not figured or figured only in scanning electron microscopy (SEM) are described in Appendix B in the electronic supplementary material.

\section{(a) Ostrich}

Femora and tibiae were collected after ca 5 days of natural degradation in very warm and humid conditions. Bones were defleshed, washed with $10 \%$ bleach, rinsed extensively and allowed to air dry under a fume hood. Some of the bones were darkly stained by ruptured haematoma bleeding into bone tissues. Dried bone samples were stored for ca 9 months to 1.5 years under desiccation before further processing.

Another ostrich specimen had been stored at $-20^{\circ} \mathrm{C}$ for approximately 2 years, then at room temperature for over 12 years with no treatment. Both fresh (figure $1 g$ ) and older (figure $1 f, h-j$ ) demineralized bone matrix exhibited dense, fibrous morphology and stiff resilience, characteristic of collagen. Osteocytes were visible within the fibrous matrix after staining (figure $1 f$ ) and, along with vessels, were liberated after enzymatic digestion of the matrix. Vessels were transparent and flexible, varied in diameter and often occurred as a geometric three-dimensional network (figure $1 \mathrm{~g}$ ). Endothelial nuclei on vessel surfaces were enhanced with fixation (Schweitzer et al. $2005 a$, electronic supplementary material). While few distinct red blood cells were visible, some vessels contained dark red thickened material, and abundant fatty tissues remained associated with the vessels after treatment (figure $1 h$ ). Osteocytes were elongate, and they retained extensive filipodia and intracellular contents (figure $1 i, j$ ).

Transmission electron microscopy (TEM) showed collagen fibres with a characteristic $67 \mathrm{~nm}$ banding pattern and osteocytes with intact lipid bilayer and nuclear membranes (not shown). Chromatin was visible inside the nuclei (not shown).

\section{(b) Emu}

After approximately 2 years of burial and natural degradation, femora and tibiae were clean with no visible remnants of skin, muscle or connective tissue. Demineralized matrix was dense and fibrous, and it contained osteocytes and naturally pigmented vessels (figure $1 a, b$ ). SEM revealed fibre bundles with virtually no difference between this $3+$ year post-mortem specimen (figure $4 b$ ) and that of fresh chicken (figure $4 a$ ).

Enzymatic digestion produced translucent interconnected vessels pigmented with presumed haemoglobinderived compounds (figure $1 b, c$ ) and transparent osteocytes with filipodia and internal contents (figure $1 d, e$ ). Some vessels were invaded by fungal hyphae (not shown). Under TEM, collagen fibres were identified by a $67 \mathrm{~nm}$ banding pattern, and osteocytes with lipid bilayer membranes and chromatin were visible (not shown).

\section{(c) Moa (MOR OFT255, 800-1000 years)}

The demineralized pigmented matrix was soft, fibrous and pliable, yet retained shape and volume, much like modern bone (figure $2 a$ ). SEM (figure $4 c$ ) revealed virtually no morphological changes when compared with ostrich and emu tissues. Supernatant after demineralization was dark brown, as in much older specimens.

Blood vessels, either free-floating or emerging from pliable collagen matrix (figure $2 b$, inset, $d$ ), were transparent and, in some cases, infiltrated with contaminating fungal hyphae and/or spores. The hyphae were completely distinct from the vessels. Hyphal diameter was significantly less than that of vessels, hyphae were septate and, unlike vessels, did not taper at branch points (not shown). Spores were discernible as small dark round bodies (figure $2 b$, arrows), distinct from larger translucent red intravascular structures.

Osteocytes were completely transparent with a threedimensional array of supple filipodia (figure $2 e$, arrow), often interconnected to form a multicellular mass (figure 2c). Osteocytes were free-floating, embedded within the collagen matrix or closely associated with vessel surfaces.

\section{(d) Columbian mammoth (MOR 604, $300 \mathrm{ka}$ )}

Flexible, fibrous matrix was less intact, thinner and more transparent than more recent material after demineralization. Fibres were visible (figures $2 f$ and $4 e$ ), but in some regions, matrix was surrounded by a hard red/orange mineralized crust (not shown). Matrix digested to 

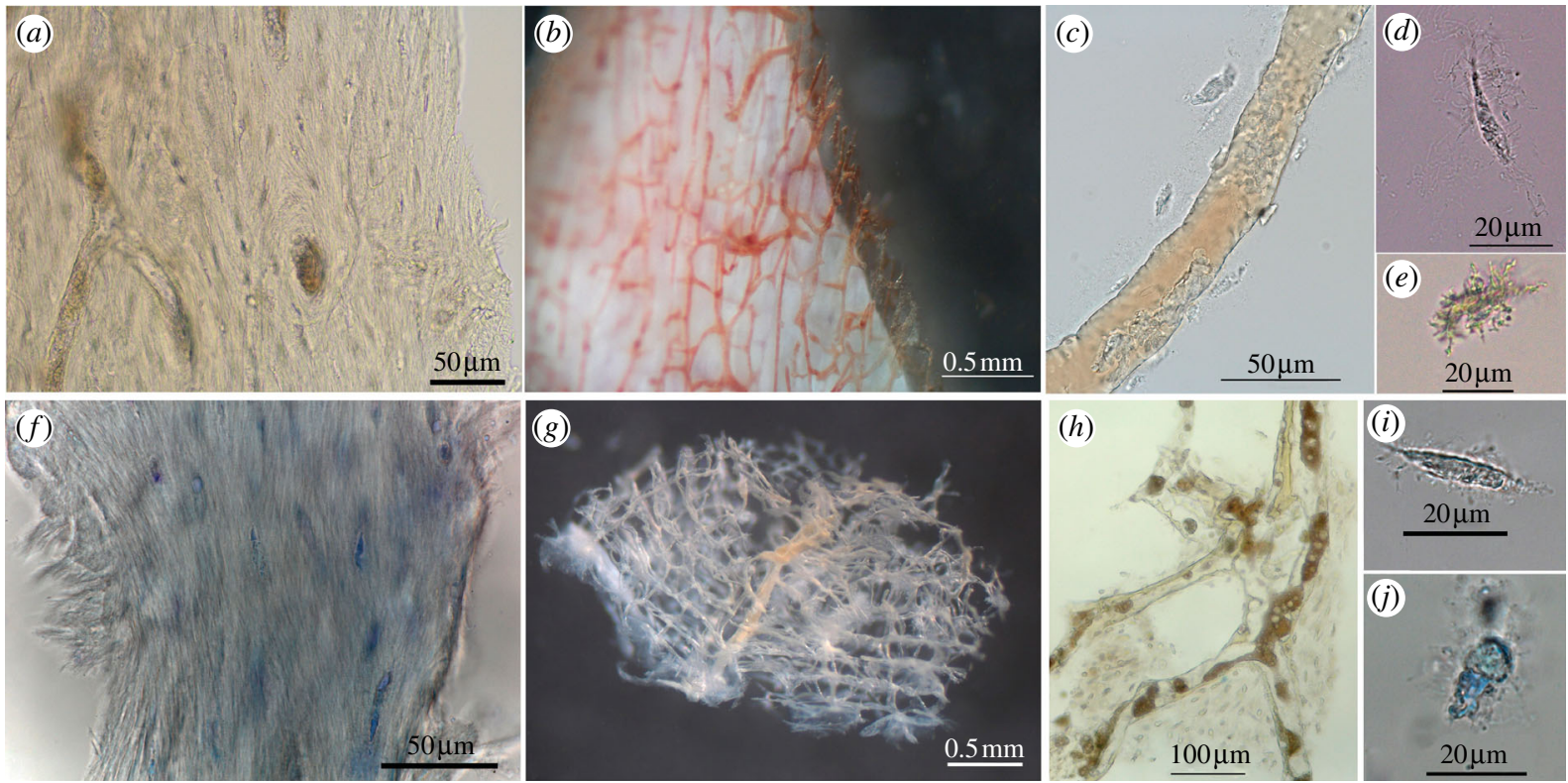

Figure 1. Tissue and cells from extant ostrich and emu. (a-e) Emu. (a) Fibrous texture of demineralized cortical bone matrix. Osteocytes and vessel channels are visible. (b) Vessels emerging from demineralized cortical bone fragment, after partial enzyme digestion. Pigmented blood products fill vessel lumen. (c) Isolated vessel shows intimate association with osteocytes. (d,e) Isolated osteocytes with radiating filipodia, liberated after collagenase digestion of cortical bone. Variation in degree of pigmentation is seen, as well as variation in overall cell shape. $(f-j)$ Ostrich. $(f)$ Histochemical staining emphasizes fibrous texture of demineralized ostrich cortical bone matrix. Osteocytes are interspersed with collagen fibres. $(g)$ Interconnecting lattice of vessels liberated from fresh ostrich cortical bone after demineralization and enzymatic digestion as above. $(h)$ Ostrich vessel and associated matrix with osteocytes after demineralization and digestion. Blood breakdown products fill vessel lumen. (i) Unstained, isolated osteocyte is elongate with extensive filipodia. $(j)$ Cell body is expanded and has been stained to reveal cellular detail. All specimens derived from $14+$ year post-mortem specimen except $(g)$, from $c a 1$ year post-mortem. Scale bars are as indicated.

completion with collagenase, but fibrous sheet material associated with vessels did not (table 1).

Translucent, hollow and flexible blood vessels associated with fibrous sheet material (figure $2 g$ ) were pigmented light to dark orange, but colour was not correlated to flexibility, as other vessels, similarly pigmented, were hard and crystalline (figure $2 g$, inset). Small oval red-tinted microstructures were visible within vessels (figure $2 i$ ) and appeared biconcave and anucleate under transmitted light microscopy (not shown). These structures vary in diameter, but in morphology and location, they are consistent with mammalian red blood cells. Osteocytes with elongate cell bodies and extensive filipodia were free-floating, bound within the fibrous matrix or associated with vessel surfaces (figure $2 f, h, j$ ).

\section{(e) American mastodon (MOR 605, $300 \mathrm{ka}$ )}

Demineralized fibrous bone matrix was fragmented, with abundantly distributed nucleated osteocytes having extensive filipodia, seen in transmitted light (figure $2 k, p$, arrow) and SEM (figure $4 f$ ). Osteocytes were free-floating (figure $2 m-p$ ) and often interwoven to form a multicellular mass, as seen in moa (figure $2 c$ ). Vessels were mostly crystalline and pigmented (figure $2 l$ ), and only small fragments of soft vessels were observed (figure $2 l$, inset). Most of the matrix responded to collagenase digestion, but some undigested, fibrous sheet remained associated with the vessels (not shown).

\section{(f) Tyrannosaurus rex (MOR 555, $65 \mathrm{Ma}$ )}

Cortical bone fragments demineralized over several weeks showed variable preservation. Some fragments yielded soft, pliable and fibrous matrix, while others were unaltered and remained crystalline after more than two months. Demineralization was slower and the resulting supernatants were dark brown, when compared with extant samples. Pliable, fibrous sheet matrix did not respond to collagenase digestion. Scattered osteocytes were present within fibrous tissue (figure 3a), and under SEM, demineralized matrix was morphologically similar to other matrix tissues (figure $4 g$ ), particularly, the much younger mastodon (figure $4 f$ ).

After two months of demineralization, pigmented vessels (figure $3 b$ ) were present in some fragments. A sheath of crystalline material was present on some bone surfaces (not shown) after prolonged exposure to ethylenediaminetetraacetic acid (EDTA). Transparent vessels were hollow, as evidenced by visible menisci (not shown), and were joined in a distinct network (figure $3 b$ ) similar to ostrich (figure $1 g$ ). Some vessels remained within fibrous matrix, and round red microstructures with opaque central regions (figure $3 c$ ) similar to those previously reported (Schweitzer et al. $1997 a, b$; Schweitzer \& Horner 1999) were observed within.

Osteocytes with apparent nuclei were visible at higher magnifications (figure $3 d$ ). The elongate cell bodies had long, supple filipodia, some were colourless and others slightly pigmented. In other fragments, osteocytes and vessels remaining after dissolution of the mineral phase were more visibly altered, with regions of orange-red pigmentation and shorter filipodia (figure $3 e$ ). 


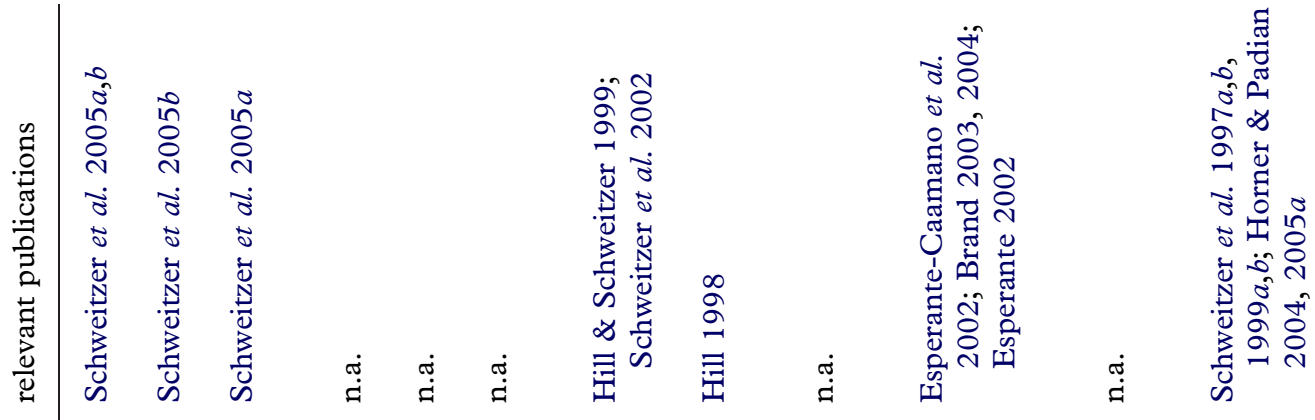

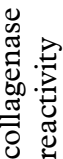

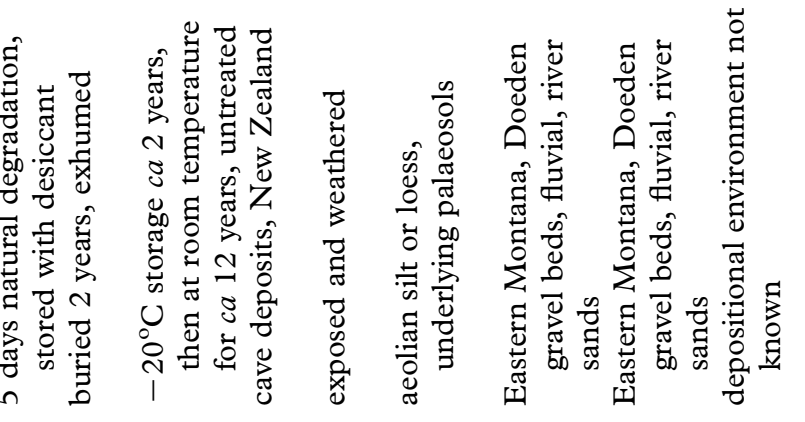

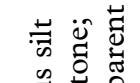

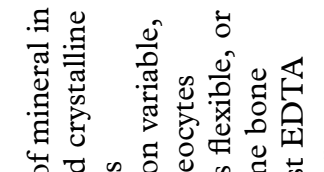

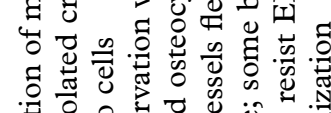

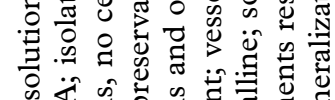

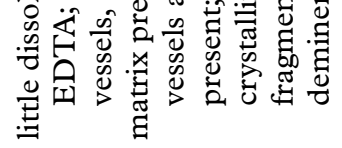

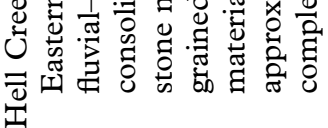

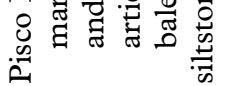

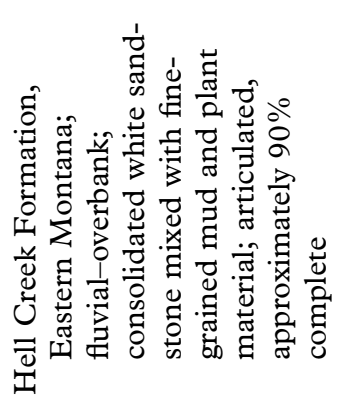

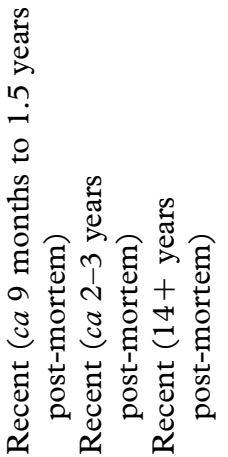

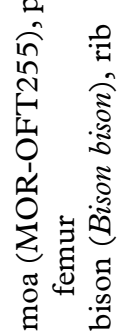
密

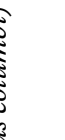

है

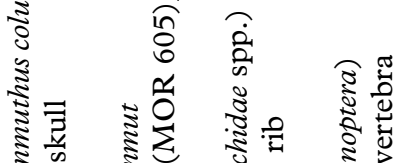
密令 帘

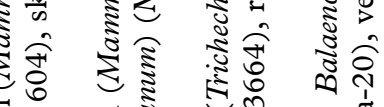
害吕

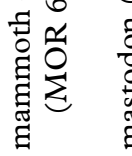
हี है

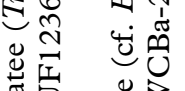

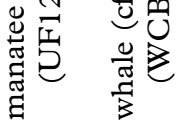
के हि 先 告 ฐँ

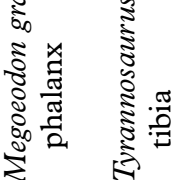

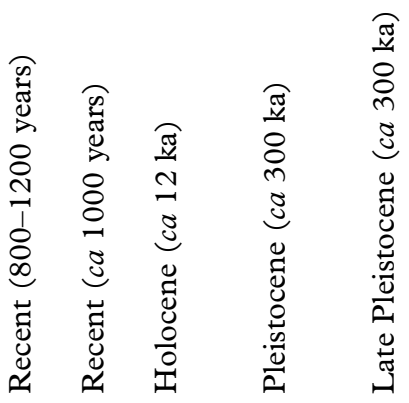

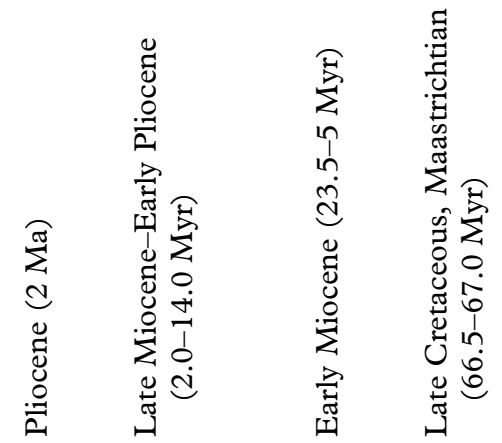




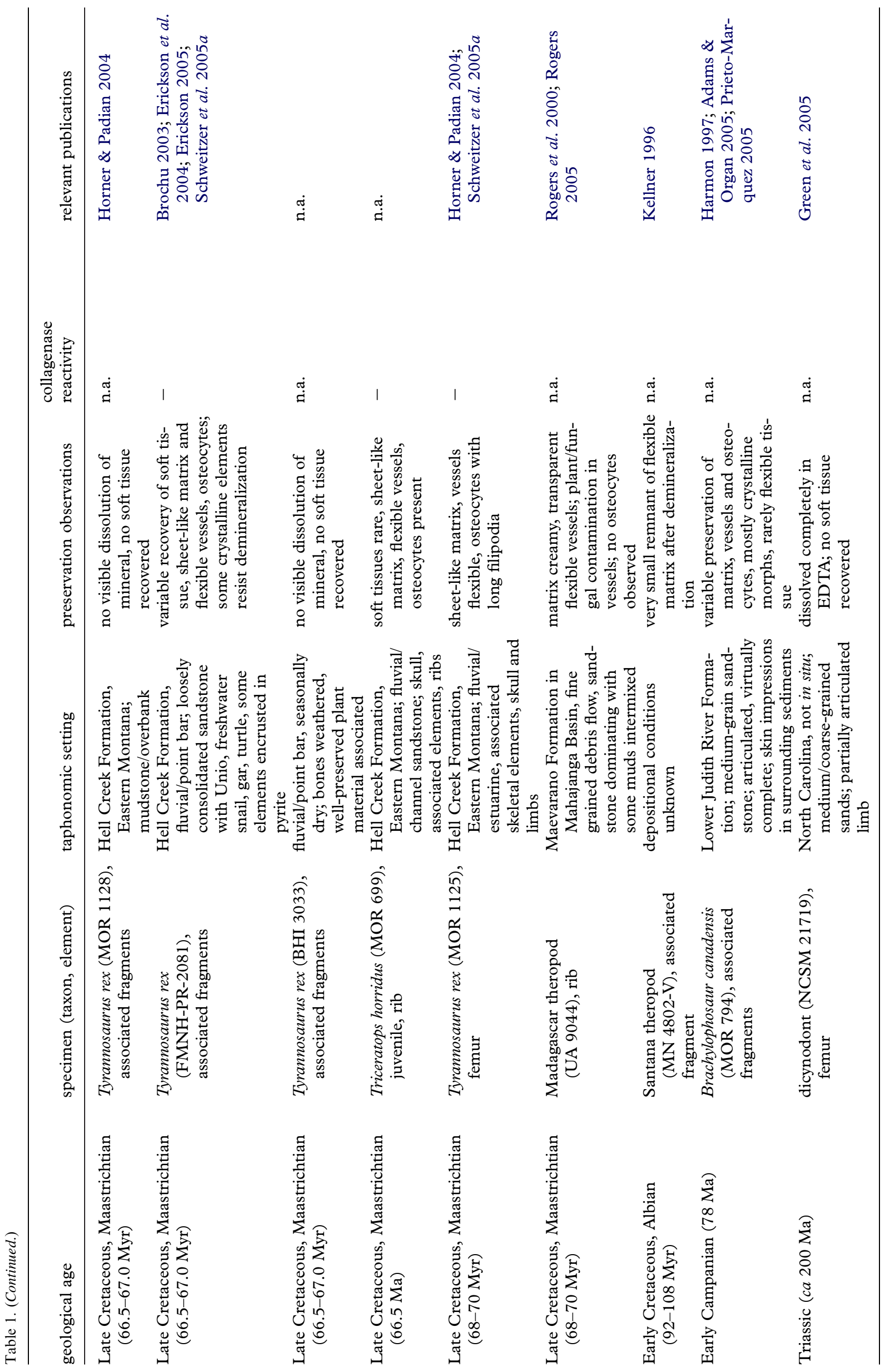



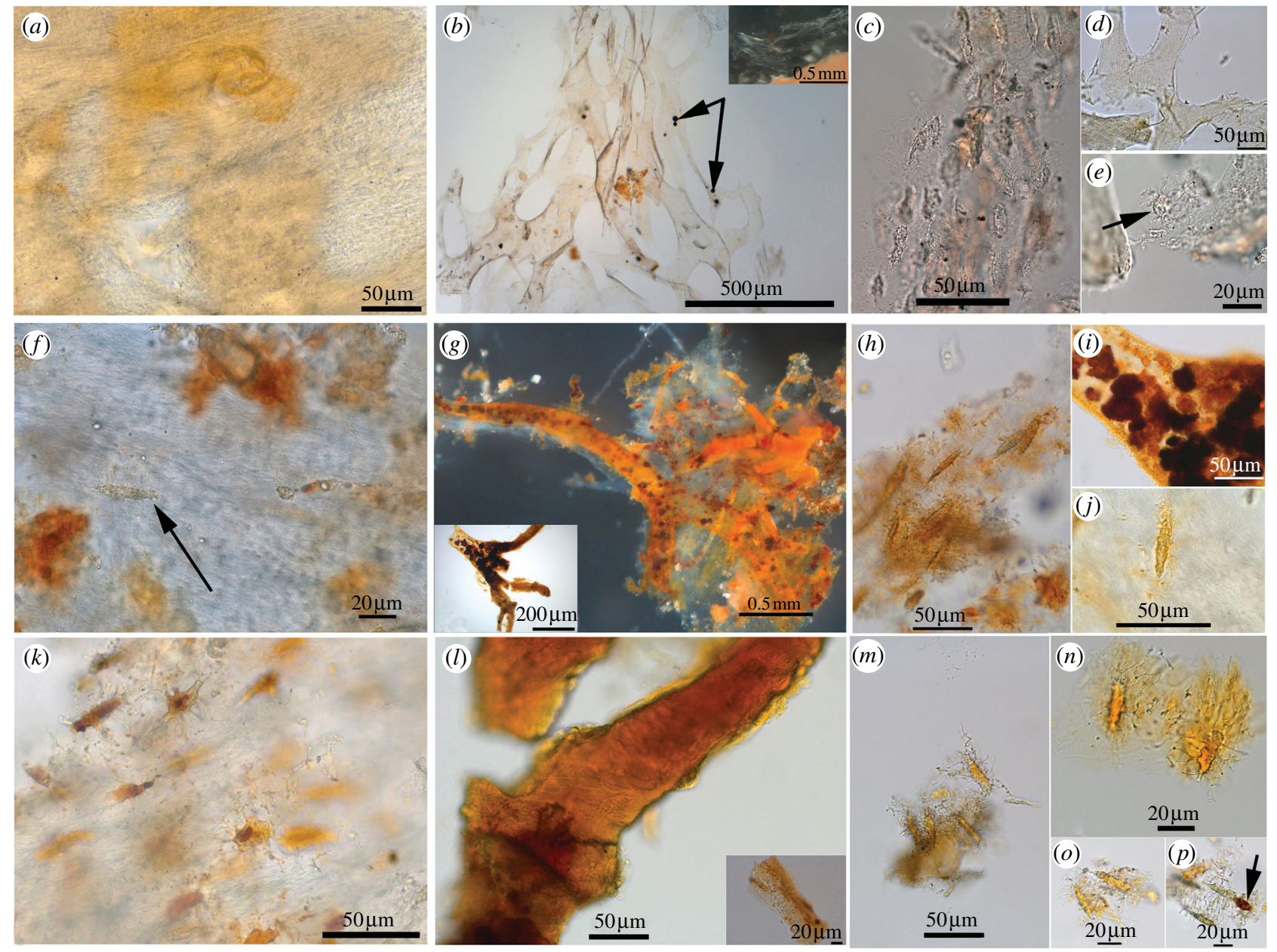

Figure 2. Tissue and cells: moa, mammoth, and mastodon. (MOR OFT255, $a-e$ ) Moa. (a) Fibrous texture, embedded osteocytes and natural pigmentation of demineralized cortical bone. Vessels are not apparent in this image. (b) Interconnecting network of isolated, transparent vessels, with dark-bodied fungal spores visible within vessel lumen (arrows). Inset shows vessels emerging from digesting bone fragment. (c) Enzyme-resistant tissue associated with osteocyte cell bodies. (d) Isolated fragment of vessel shows natural pigmentation. (e) Transparent, round-bodied osteocyte (arrow) with radiating filipodia, still closely associated or attached to remnants of fibrous matrix. (MOR 604, $f-j$ ) Mammoth. $(f$ ) Demineralized mammoth skull fragment shows uneven pigmentation and osteocyte (arrow) with filipodia within fibrous matrix. $(g$ ) Flexible, deeply pigmented vessels with associated matrix (white) sheet material. Vascular contents appear as deeply pigmented microstructures. Inset shows vessel with similar pigmentation and internal microstructures, but crystalline, not flexible. $(h)$ Flexible, fibrous matrix containing multiple pigmented osteocytes with interconnecting filipodia. (i) Vessel shows consistent wall thickness and intravascular material. $(j)$ Orange-pigmented osteocyte with filipodia radiating outward into fibrous matrix. (MOR 605, $k-p$ ) Mastodon. ( $k$ ) Fibrous texture of demineralized matrix encloses abundant, naturally pigmented osteocytes, with distinct nuclei and long filipodia extending into matrix fibres. ( $l$ ) Fragmented and deeply pigmented crystalline vessel. Inset shows another vessel fragment with crystalline surface structure. $(m-p)$ Osteocytes with interconnected filipodia, some showing distinct nuclei ( $p$, arrow). Scale bars are as indicated.

(g) Tyrannosaurus rex (FMNH-PR-2081, $65 \mathrm{Ma}$ )

Cells, matrix and vessels were initially reported for this specimen in 2005 (Schweitzer et al. 2005a,b, electronic supplementary material), but additional details are reported here. A dark crystalline crust covered some regions of bone, which was emphasized with increasing duration of demineralization. Small regions of soft tissue were recovered, but most bone material was crystalline and deeply pigmented, after months in solution. SEM imaging showed morphological similarity to other tissues (figure $4 h$ ), but some alteration is apparent. Osteocytes with long filipodia and distinct, well-defined 'nuclei' (Schweitzer et al. 2005a, electronic supplementary material) were restricted to pliable regions of matrix, and no free-floating osteocytes were observed. Flexible vessels were not as transparent as in other specimens, but were populated with uniformly oval, red-pigmented, translucent microstructures with opaque central cores (Schweitzer et al. 2005a, electronic supplementary material).

\section{(h) Triceratops horridus (MOR 699, $65 \mathrm{Ma}$ )}

Demineralized matrix was thin, flexible and fibrous, and emerged as sheets of material (figure $3 f$, and inset) unresponsive to collagenase. Hollow, transparent and flexible vessels were slightly pigmented (figure $3 g$ ). Vessels of varying diameters branched and tapered, and some contained red spheres that varied slightly in diameter (figure $3 h, k$ ). Osteocytes were not plentiful, but those observed had pigmented elongate cell bodies, some with internal contents and short, stubby filipodia (figure $3 i, j$ ).

\section{(i) Tyrannosaurus rex (MOR 1125, 68 Ma)}

Although some morphological data were previously reported (Schweitzer et al. 2005a), further observations 


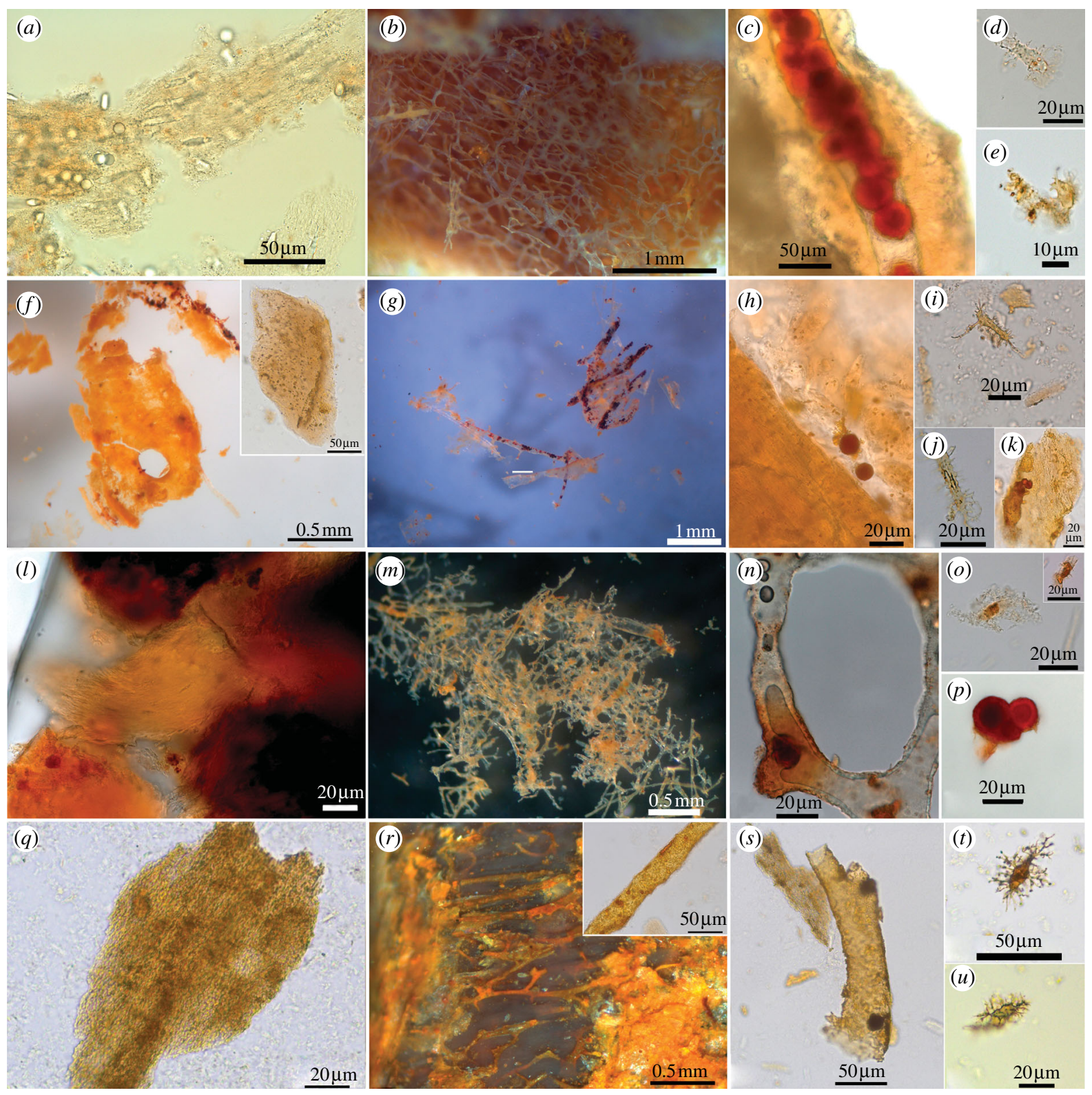

Figure 3. Soft tissue and cells from selected dinosaur specimens. (MOR 555, a-e) Tyrannosaurus rex. (a) Fragment of demineralized, flexible cortical bone matrix with fibrous texture. Transparent osteocytes are visible among the matrix fibres. (b) Interconnected network of transparent and/or lightly pigmented vessels, released after demineralization. Vessels are hollow and supple. (c) Vessel fragment filled with small red microstructures with opaque centres, surrounded by fibrous bone matrix containing osteocytes. Pigmentation is natural. (d) Internal, intracellular contents are visible in isolated osteocyte with filipodia. (e) Filipodia associated with small fragment of fibrous matrix. (MOR 699, $f-k$ ) Triceratops horridus. $(f$ ) Deeply pigmented, flexible matrix tissue with vascular channel in centre. Inset shows fibrous matrix with pigmented spaces representing retained osteocytes and partial vessel. $(g)$ Isolated transparent vessels containing darkly pigmented intravascular structures. Vessels were rare in this specimen. (h) Round red microstructures associated with longitudinal space, possibly representing vascular canal running through demineralized fibrous matrix. $(i, j)$ Isolated osteocytes with long filipodia. ( $k$ ) Vessel fragment showing surface texture and natural pigmentation. (MOR $1125, l-p$ ) Tyrannosaurus rex. (l) Fragment of demineralized, naturally pigmented fibrous matrix tissue containing osteocytes. $(m)$ Interconnected, flexible, transparent vessels with pigmented intravascular structures with varying diameters similar to extant vessels. (n) Vessel with hollow lumen and uniformly thick vessel wall, containing deeply pigmented intravascular microstructure. (o) Isolated, free-floating osteocytes, with long, extensive filipodia and intracellular contents. $(p)$ Three naturally pigmented intravascular microstructures with opaque centre, expressed from vessel. (MOR 794, $q-u$ ) Brachylophosaur canadensis. (q) Flexible, fibrous demineralized bone matrix with variable pigment distribution. ( $r$ ) Orange-pigmented vessels, either crystalline or flexible. Flexible vessel walls, less transparent than in other dinosaurs (Inset). $(s)$ Isolated, flexible branching vessel with intravascular contents. $(t, u)$ Naturally pigmented osteocytes with extensive three-dimensional filipodial network. Scale bars are as indicated.

show widely varied preservation of cell and tissue components. Soft matrix tissues were rare, but when recovered, they were fibrous and deeply pigmented (figure $3 l$ ), and often present as thin degraded 'ribbons', highly altered from younger (less than $500 \mathrm{kyr}$ ) specimens, but similar to other dinosaurs.
Flexible vessels (figure $3 m, n$ ) and osteocytes (figure $3 o$, inset) were much more common than matrix in this specimen. Vessels from many demineralized fragments were consistently flexible, hollow and translucent with slight pigmentation (figure $3 m, n$ ). Osteocytes varied, with some transparent and containing a definite, well-defined 

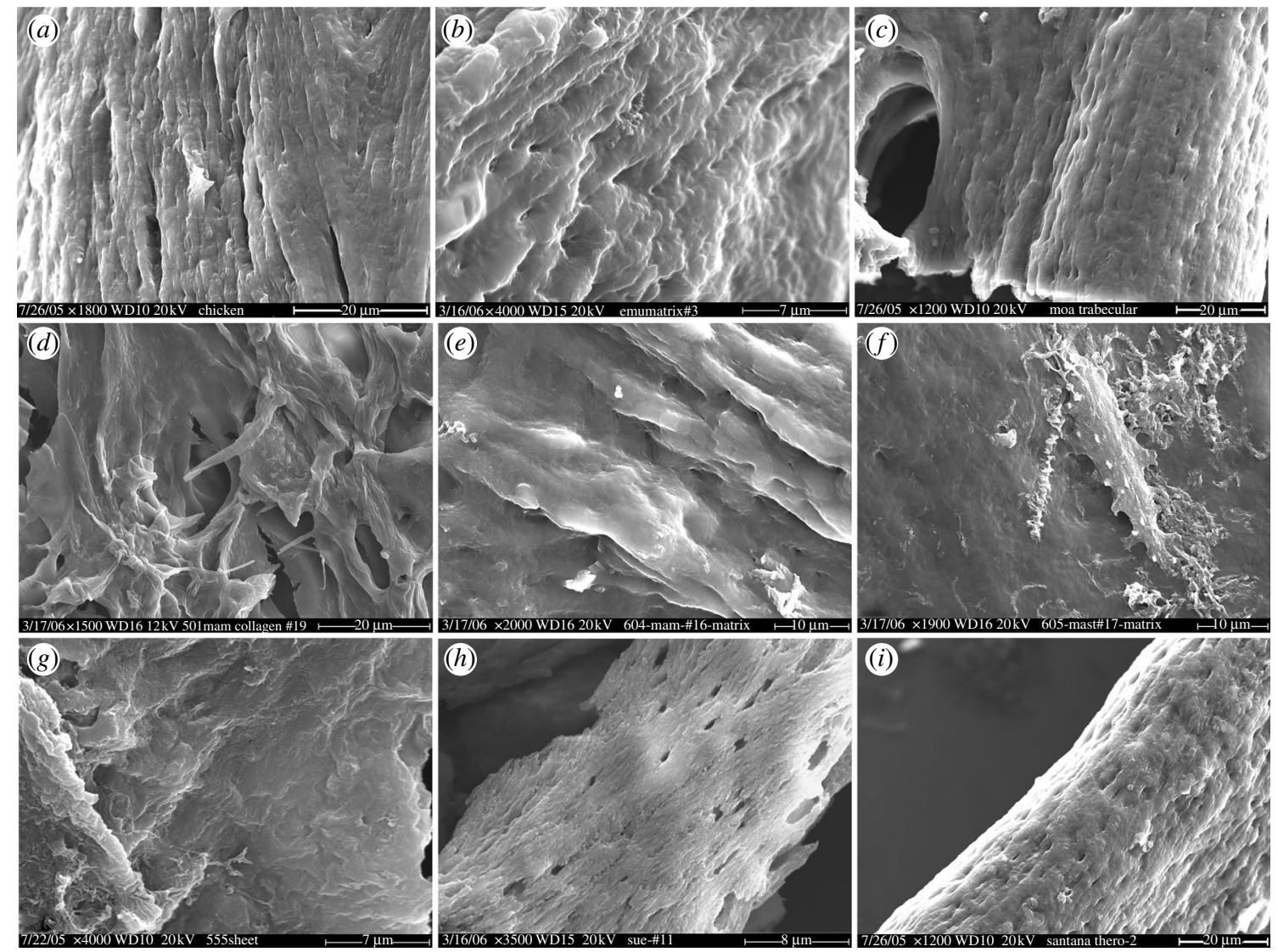

Figure 4. SEM of demineralized bone matrix from multiple specimens. (a) Fresh chicken showing fibre bundles. Crossbanding is not within SEM resolution capability. (b) Emu matrix, with fibre bundles at higher magnification. (c) Moa trabecular bone (MOR OFT255). (d) Mammoth (MOR 91.72). (e) Mammoth (MOR 604). ( $f$ ) Mastodon (MOR 605). Featureless matrix is impossible to image without also imaging osteocytes (centre). (g) Tyrannosaurus rex (MOR 555). (h) Tyrannosaurus rex (FMNHPR-2081). ( $i$ ) Theropod indeterminant (MN 4802-V). Magnifications and scale bars are as indicated.

'nuclear' region and very long, extensive filipodia (figure 3o), while others had short, stubby filipodia and pigmented internal contents (figure $3 o$, inset). Dense, round microstructures, tentatively correlated with intravascular microstructures observed under transmitted light and reported earlier (figure 3p; Schweitzer et al. 2005a), were isolated to vessel spaces within the demineralized matrix.

\section{(j) Brachylophosaurus canadensis (MOR 794, $78 \mathrm{Ma}$ )}

Demineralization resulted in small fragments of pigmented fibrous matrix (figure $3 q$ ), some of which contained both orange-tinted vessels and osteocytes (figure $3 r$ ). The surface of free-floating, flexible vessels appeared granular and were associated with apparent surface debris (figures $3 r$, inset). The highly fragmented vessels contained small round red microstructures (figure $3 s$ ). Pigmented osteocytes with long flexible filipodia and internal structures were recovered both within matrix and free-floating (figure $3 t, u$ ).

\section{DISCUSSION}

This study addresses the following questions: (i) how extensive is preservation of soft tissues and cells in vertebrate remains, (ii) can patterns be discerned regarding tissue/cell degradation over time and (iii) can taxonomic, temporal, geographical or geochemical factors be linked to preservation?
The occurrence of flexible, fibrous matrix, hollow transparent vessels, osteocytes and intravascular material, often with cell-like morphology, was not isolated, but observed in many specimens of different geological ages (Recent, Pleistocene, Pliocene, Miocene, Cretaceous and Triassic), depositional setting (fluvial sandstone, cave deposits, loess, siltstone, mudstone and marine) and taxonomic affinity (birds, mammals, saurischian (theropod) and ornithischian (hadrosaur, ceratopsian) dinosaurs, and dicynodont).

We tested many specimens of different geological ages (Recent, Pleistocene, Pliocene, Miocene, Cretaceous, Triassic), depositional settings (fluvial sandstone, cave deposits, loess, siltstone, mudstone, marine) and taxonomic affinity (birds, mammals, saurischian (theropod) and ornithischian (hadrosaur, ceratopsian) dinosaurs, and dicynodont) for the presence of flexible, fibrous matrix, hollow, transparent vessels, osteocytes and intravascular material. Some or all of the four elements first reported for three specimens of Tyrannosaurus rex (MOR 1125, FMNH-PR-2081, MOR 555) and Brachylophosaurus canadensis (MOR 794) (Schweitzer et al. 2005a), have now been identified in numerous fossil specimens from thousands to millions of years old (Table 1, Appendix B electronic supplementary material). However, molecular and chemical analyses of these components is not yet complete. In particular, the osteocytes and round red vascular microstructures represent a significant technological challenge for achieving isolation and chemical characterization. Results of these ongoing studies will be reported elsewhere. 
Preliminary research indicates that as a general rule, matrix tissues remaining after demineralization are more extensively altered morphologically than blood vessels and/or osteocytes. The progression of degradation seems to occur as follows: in recent (less than $20 \mathrm{kyr}$ ) specimens, demineralization leaves a dense, stiff and flexible tissue with structural integrity. Fibres remain in tight association and possess $67 \mathrm{~nm}$ crossbanding characteristic of collagen under TEM (not shown). Vessels and osteocytes are enclosed within the matrix and cannot be separated without enzymatic digestion. After 100-300 kyr, the matrix thins, becoming almost transparent, less stiff and more flexible, but it is still fibrous under transmitted light microscopy, similar to fresh tissues after prolonged enzymatic digestion. In most cases, vessels and cells separate easily from the thin matrix. All demineralized matrices younger than $1 \mathrm{Ma}$ including the Pleistocene mammoth and mastodon respond to collagenase digestion with definitive morphological change and, in most cases, complete dissolution of visible collagen. However, a small percentage of matrix from most of these samples, including recent ones, does not digest, but remains as a transparent, fibrous and very thin sheet associated with and attached to some vessels, in which osteocytes can be observed. This indigestible tissue is seen in fresh bone and is identical in morphology to similar material associated with some vessels recovered from fossil bone elements.

These morphological data indicate that material persists in fossil bone which is intimately associated with the mineral phase, but that upon demineralization retains morphological aspects of the original organic and cellular components of bone, such as fibrous texture (matrix), transparency, flexibility, suppleness, hollow lumen (vessels) as well as intravascular and intracellular components. From the limited samples examined thus far, no single environmental component has been identified as a predictor of soft tissue preservation. However, the specimens from which soft tissues are recovered predominantly derive from fluvial sandstone environments, and none were recovered from fossils preserved in terrestrial mudstone (MOR 1128) or marine sediments (UF123664 and WCBa-20), although in the latter, fragments of possible crystalline osteocytes were observed. However, specimens preserved in sandstones (MOR 1125) and sands intermixed with muds (MOR 555 and UA 9044) show soft tissue preservation, although preservation varies greatly within each specimen.

While 'organic' preservation (Butterfield 1990; Stankiewicz et al. 2000; Nguyen \& Harvey 2001; Briggs 2003; Butterfield 2003; MacNamera et al. 2006) has been linked in the literature to in situ polymerization (Stankiewicz et al. 2000) and/or the presence of environmental sulphur (MacNamera et al. 2006), there are no existing models of fossilization and/or tissue degradation allowing for the preservation of original morphology, transparency, hollow character and flexibility over geological time. The present state of knowledge holds that microbial attack, enzymatic degradation, cellular necrosis and other processes contribute to total degradation of recognizable organic materials in days to years (Ambler \& Daniel 1991; Eglinton \& Logan 1991; Hedges 2002; Tibbett et al. 2004). Yet our data indicate that, within the protective environment of recent, untreated or unfossilized bone (emu, ostrich, moa and bison), these processes may be slowed or arrested, contributing to long-term preservation of cells and tissues. It has been proposed that no original protein and/or DNA fragments can be recovered beyond ca $100 \mathrm{kyr}$ (Lindahl 1993; Bada et al. 1999; Briggs et al. 2000; Hoss 2000; Stankiewicz et al. 2000), although some remnant molecules or fragments that are less phylogenetically informative may persist up to this point under exceptional circumstances (Briggs et al. 2000). Therefore, we consider alternative hypotheses regarding the source/composition of this material, and propose a two-stage hypothesis for their persistence over geological time.

\section{(a) Alternative hypotheses for source of soft tissuelcellular structures}

The possibility remains that despite morphological and functional similarity of fossil cell and tissue components to extant material, no original molecular components may remain (Towe 1980). The structures may be the result of an as yet unidentified abiotic or geomicrobiological process that could explain their presence in thousand- to million-year-old fossil remains. Therefore, alternatives to the hypothesis that these structures are remnants of the original material are presented below.

\section{(i) Intravascular microstructures}

Red blood cells can persist morphologically for thousands of years (e.g. Maat 1991, 1993), and some components of avian red blood cells, possibly shared by dinosaurs, may increase longevity of these structures (Nikinmaa 1990; Cohen 1991; Schweitzer et al. 1997b; Schweitzer \& Horner 1999). The structures observed in most fossil specimens are similar in morphology, size, location and content to erythrocytes observed in related extant taxa. However, under restricted environmental conditions, reduced iron as pyrite may form round clusters of regular crystals known as framboids (Martill \& Unwin 1997). We previously argued against pyrite as a source for these intravascular microstructures (Schweitzer \& Horner 1999), because specimens differed widely from criteria for pyrite formation and composition. The consistent location of these microstructures only to vascular channels across numerous taxa from varied depositional environments suggests a common origin that is not the strict result of depositional geochemistry, and little or no sulphur is identified in any of the microstructures examined for composition, eliminating the possibility that these are pyritic. However, to demonstrate conclusively that these objects are related to the original blood components would require positive identification of haem compounds isolated from these microstructures. Definitive experiments are planned for the near future. Until such results are obtained, however, a geological explanation for the presence of these intravascular microstructures has not been eliminated.

\section{(ii) Vessels}

As arguably the most labile and easily degraded of the structures we observed, the presence of soft vessels is enigmatic. They are neither biomineralized nor have any obvious inherent characteristics that would favour preservation, such as the resistance to degradation of extracellular collagen (Tuross 2002). Various sources for these structures were considered, including contamination by field-applied preservatives. Deep internal bone fragments 
were microscopically examined prior to treatment to exclude glues or preservatives, but the possibility exists that chemicals applied to the outermost surfaces might have been drawn into porous vessel channels. Because virtually all vertebrate palaeontological materials, with the exception of isolated fragments or 'float', are treated to prevent destruction during recovery, this possibility must be considered. Common field preservatives such as polyvinyl acetate or alcohol (PVA), vinyl acetate (Vinac) or polyvinyl butyral (Butvar) are applied as a very thin acetone-based solution that polymerizes upon evaporation of solvent. These preservatives are assumed not to penetrate deeply, but this has not been experimentally tested for porous fossil bone.

Beyond microscopic lack of evidence, we have tentatively eliminated preservatives as a vessel source for the following reasons. First, field preservatives are applied to external surfaces of horizontal bone, at essentially right angles to the longitudinally oriented Haversian systems. If the fluid entered vascular canals, it would most probably spread laterally under gravitational influence. This dispersal would probably not yield three-dimensional networks of interconnected vessels, hollow lumen or vessel walls of uniform thickness, but would result in structures consistently thicker on the 'down' side. Capillary action, a second mode of fluid spread, does not adequately explain the uniform thickness and branching networks of vessels observed. In addition, capillary flow is usually disrupted by impurities, and it is unlikely to occur around intravascular material. Second, we have noted the preservation of soft vessels in field float and other specimens never exposed to any preservative or glue, and the texture of these vessels under SEM (not shown) is identical to those figured in other fossil specimens (e.g. MOR 1125; Schweitzer et al. 2005a) and very different from imaged PVA (personal observation, data not shown). Third, invasive polymeric preservatives are known to require extensive, controlled perfusion, as osmosis and/or capillary action is not sufficient for adequate penetration. Efforts to replicate vasculature with polymers do not allow for free-floating microstructures inside vessels, produce extensive filling defects and do not form lumen (Hirschberg et al. 1999). Finally, when polymerized PVA and recovered dinosaur vessels were visualized under SEM, PVA responded to the electron beam with immediate swelling and cracking of material, resulting in significant alteration (personal observation, not shown). Vessels showed no change in morphology, even under long duration of beam exposure.

The vessels could be composed of kerogen, operationally defined as 'organic constituents of sedimentary rocks that is neither soluble in aqueous alkaline solvents nor in common organic solvents' (Tissot \& Welte 1984, p. 131), or in other words, organic material remaining after dissolution of surrounding material. The relatively high carbon content of these vessels may fit this definition, but vessel carbon is reduced relative to extant material (Schweitzer et al. 2005a, SOM). Additionally, most described kerogen is not transparent or translucent, as are these vessels, and we have found that at least in some cases, the vessels are easily solubilized in some polar solvents, indicating the possible presence of lipids. Because phospholipids are a significant component of cell membranes, further testing may demonstrate an early stage in polymerization.

Fungal invasion was considered as a source of the vessels, but when transparent vessels were invaded by hyphae, the hyphae exhibited standard fungal morphology, including septation and retention of overall diameter at branch points, easily distinguishing them from vessels. The observed vessels taper at branch points, do not possess septae and are uniformly greater in diameter than hyphae. In addition, vessel texture is completely distinct from that of hyphae under SEM (not shown). Whether the observed fungi are recent invasion or concurrent with degradation and subsequent fossilization of specimens has not yet been determined, but fungal hyphae are sufficiently distinct in structure to eliminate as a source of vessels.

The possibility that microbes may have invaded bone and vascular channels after death, secreting extracellular polymeric substances (EPS) that subsequently mineralized, was also considered. If deposition of mineral upon microbial biofilm allowed retention of flexibility in one case, it is feasible to propose that the same process contributed to the preservation of the original vessel walls. Additionally, as with polymers, microbial biofilms would not uniformly coat all vessel channels to leave extensive networks of hollow tubes with uniform wall thickness. However, further molecular analyses will be employed to eliminate EPS as a source for these vessels.

Finally, the possibility that the vessels represent altered remnants of the original lipid components of cell membranes was considered. Some preliminary analyses are consistent with this interpretation; thus, this possibility has not been eliminated as the primary constituency of preserved vessels in fossil bone. Altered lipids that persist across millions of years may not be as informative as original proteins or DNA, but a mechanism resulting in their preservation and polymerization is worthy of investigation.

\section{(iii) Fibrous matrix}

The fibrous matrix visible after demineralization would be a sufficient evidence for collagen if specimens were extant. Indeed, the $67 \mathrm{~nm}$ banding patterns seen in TEM of more recent specimens, including Pleistocene material, are diagnostic of collagen (not shown). The data for older specimens are ambiguous and do not uniformly support remnant collagen as a source for this material, although many tests are consistent with this interpretation. These analyses are ongoing and the chemical nature of the fibrous material will be reported elsewhere.

\section{(iv) Osteocytes}

While Schweitzer et al. $(2005 a, b)$ are not the first to report osteocytes preserved in dinosaur bone (Pawlicki et al. 1966; Pawlicki 1995; Pawlicki \& Nowogrodzka-Zagorska 1998), they were the first to demonstrate that these structures retained internal contents, original transparency and flexible, supple and, in some cases, extensive filipodia. We have been unable to postulate alternative hypotheses consistent with all the data regarding the source of these microstructures, and pending further analyses, consider these cell-like structures to be remains of original cells. 


\section{(b) Proposed hypothesis regarding mechanisms of preservation}

Data show that contrary to proposed degradation models (e.g. Usui et al. 1989), osteocytes may remain intact in extant bone for relatively long post-mortem time periods, without major morphological change. TEM reveals intact cell membranes, organelles and chromatin in osteocytes preserved in untreated bone (not shown) after 2-3 years of natural degradation or longer. Likewise, endothelial cell nuclei are identified on intact and aldehyde-fixed vessel surfaces from untreated $14+$ year post-mortem specimens (Schweitzer et al. 2005a). Therefore, for at least a significant initial period, no chemical modification may be required to protect cells, tissues and vessels beyond the intimate association with mineral found in bone (Weiner \& Traub 1989; Weiner et al. 1989; Glimcher et al. 1990; Sykes et al. 1995; Trueman \& Martill 2002; MacNamera et al. 2006).

The vessels and the cells in fossil material might have avoided initial degradative reactions owing to sequestration within bone matrices and protective association with minerals (Glimcher et al. 1990; Sykes et al. 1995; Trueman \& Martill 2002; Schmidt-Schultz \& Schultz 2004; Salamon et al. 2005). Additionally, breakdown of haemoglobin and myoglobin after death may have contributed to this initial preservation, as free haem has been shown to inhibit enzymatic degradation (Francis et al. 1997) and cellular autolysis (Ferris et al. 1988; Lee \& Fein 2000; Wightman \& Fein 2005 and references therein). However, at some point beyond this initial phase, a mechanism must exist for continued preservation of these labile components. Pending the verification of endogeneity of the cells and the tissues described herein, a hypothesis is presented outlining two possible mechanisms that may combine to facilitate preservation of original organic material.

The entrance of material into the fossil record is largely a function of organismal composition and/or structure, and environmental factors. This is particularly true with respect to molecular preservation (Briggs 2003). Preservation over geological time involves transformation of labile molecules, cells and tissues from the living state to a more stable form (Eglinton \& Logan 1991; Briggs 2003). Processes resulting in such changes include polymerization and/or cross-linking of organic components (Schafer et al. 2000; Stankiewicz et al. 2000; Briggs 2003), protein polycondensations and/or clusters (Rank et al. 1985; Corbett \& Golan 1993), and lipid peroxidation of membranes (Schafer et al. 2000).

These processes can be mediated by unstable metal ions which catalyse the formation of oxygen free radicals (Gutteridge et al. 1981). Free radicals, owing to their unstable electron state, will react rapidly with organic molecules to form peroxides, which trigger chain reactions that form durable, usually irreversible cross-linkages (Schafer et al. 2000). The hypothesis presented here is that these chain reactions are triggered by post-mortem degradation of haemoglobin and myoglobin. The iron bound to haem chromophores in these molecules exists in the reduced (ferrous, $\mathrm{Fe}^{2+}$ ) state, but after protein degradation, the haem is oxidized to the ferric $\left(\mathrm{Fe}^{3+}\right)$ state (Francis et al. 1997). The electrons liberated by oxidation react with molecular oxygen to produce reactive oxygen species and highly reactive free radicals (superoxides, hydroxyl radicals and/or hydrogen peroxides). Free iron, also released by degradation of ATP, $\mathrm{ADP}$ and cystosolic citrate, participates in these reactions to form iron-oxygen complexes (Schafer et al. 2000; Mladenka et al. 2006). The oxygen radicals or iron-oxygen complexes contribute directly to the formation of cross-links between cell membrane lipids, making them inert to other degradative reactions. This chain reaction may not only explain the persistence of osteocyte cell membranes over time, but also blood vessels which, in living organisms, consist of endothelial cells with fatty acid-rich membranes are bound to one another by tight junctions.

Iron-triggered cross-linking of organic components, however, is not sufficient to explain the persistence of soft tissues across geological time. It is proposed herein that the second step in this process is mineralization of tissue and cell surfaces through phosphatization in a process similar to bone formation.

In order to preserve very labile soft tissues in fossils, one criterion is the early, rapid authigenic mineralization (Briggs 2003) via phosphatization, which can occur virtually immediately after death in appropriate environments (Briggs \& Kear 1993; Martill 1994), thus preserving cells and subcellular detail faster than they decay (Martill 1990, 1994; Wilby \& Whyte 1995; Butterfield 2003). Mineralization occurs through early infiltration and permeation of labile tissues by mineralcharged water (Schopf 1975; Allison 1988; Briggs 2003) and differs from petrification, which is a replacement process (Briggs 2003). Mineralization has been invoked to explain preservation of three-dimensional remains of non-biomineralizing organisms dating to the Neoproterozoic (Hubert et al. 2005), Cretaceous muscle fibres (Martill 1990, 1994) and other soft tissue remains. The degree of soft tissue preservation is dependent upon mineral deposition outpacing the rate of decay of the tissues (Allison 1988). Phosphatization is best known to occur in marine sediments, where waters are supersaturated with respect to phosphate (Zhu et al. 2005).

In most cases, carbonate precipitation is favoured over phosphate mineralization (Briggs 2003). However, microbial metabolism, through the degradation of large biomasses and localized reduction of $\mathrm{pH}$, may result in the preferential precipitation of apatite over carbonate (Allison 1988; Briggs 2003). In the local environment of bone, the concentration of microcrystalline hydroxyapatite (HA) liberated from solubilization of bone mineral (Wilby et al. 1996) is greater than that of carbonate, even in terrestrial settings, and would not be rate-limiting. The fidelity and detail preserved by phosphatization is influenced by the size of apatite crystals depositing on the organic substrate (tissues or cells), with crystals less than $30 \mathrm{~nm}$ providing the best and most detailed preservation (Martill 1990; Wilby 1993). Much of the mineral incorporated into bone consists of similarly microcrystalline $\mathrm{HA}$, which is removed early in bone diagenesis (Weiner et al. 1993; Lee-Thorp 2002) and available for re-precipitation onto vessel and cell surfaces.

In a process similar to template-directed assembly (Weiner et al. 1999; Mann et al. 2000), deposition of mineral crystals on normally flexible collagen molecules 
during biomineralization imparts rigidity and strength to the matrix, but when the minerals are subsequently removed, the matrix again becomes flexible - a model for the process we propose. During mobilization of microcrystalline HA in early diagenesis, characteristics of organic matrix, vessel or cell surface would dictate the emplacement of mineral crystal through mineral attraction to specific functional molecular moieties on the surface of the structure. For example, it is well recognized that vascular endothelium exhibits molecular heterogeneity, depending upon both function and tissue localization (e.g. Trepel et al. 2002). We posit that the endothelium of blood vessels in bone may have receptors that encourage mineral deposition, that the mineral depositing on the vessels may originate from slight mobilization of $\mathrm{HA}$ from bone and that removal of HA from the whole bone tissue results in restoration of the original characteristics of the tissue.

\section{CONCLUSIONS}

Because the persistence of still-soft vessels, matrix and cells in fossil remains millions of years old is unexpected and, if original, refutes models of degradation, decay and fossilization, it is important to document pathways and patterns that may lead to such preservation, and to propose viable and testable mechanisms for preservation based upon known and well-understood chemistry and molecular interactions.

The data presented here demonstrate the persistence of four soft tissue and/or cellular components in skeletal elements of various fossil specimens. These components exhibit varying states of alteration, some of which may be age-related and others which seem to depend more on environmental interactions. Beyond the Pleistocene, preservation of soft tissue elements is more likely in bones recovered from fluvial and/or sandstone environments, whereas bones from mudstone and/or marine environments are much less likely to produce similar structures. Additionally, soft tissues are most prevalent in specimens of Pleistocene or younger ages, and Cretaceous, although sampling of intermediate-aged specimens is limited. As they become available, intermediate-aged fossils will be examined for similar preservation; however, exceptionally well-preserved specimens suited to such investigations are not readily available for these destructive analyses.

Alternative hypotheses that do not invoke original materials as the source for these structures are presented. For example, the small round red intravascular microstructures may be a geological derivative, such as pyrite framboids. Alternative sources for the vessels are also considered, such as kerogen-derived components, remnants of mineralized microbial biofilms, extant fungal hyphae or even induced contamination from collection procedures. It is more difficult to propose an alternative origin for the fibrous and flexible demineralized matrix, or osteocytes with flexible filipodia and intracellular contents, but it may be that these materials are remnants of original proteinaceous material, highly altered by beta oxidation of original proteins to form long-chain hydrocarbon polymers that replace organic components or a similar condensation reaction.

If these components are demonstrated chemically to be original, a mechanism must exist to allow their persistence across geological time. A two-part hypothesis is proposed here. First and foremost, the protected microenvironments of dense cortical bone may work against rapid degradation, and may allow sufficient time before degradation for the formation of molecular cross-links that stabilize organic remains. These free-radical induced cross-links would provide great resistance to further degradation and allow original components to act as templates for rapid, authigenic mineralization, effectively removing organic molecules from solution and preventing further degradation. Upon removal of this re-deposited mineral phase, soft tissues and cells are released, still retaining morphological and functional aspects of the original materials. Chemical and molecular analyses of these elements are underway, and will allow the formulation of hypotheses regarding pathways of chemical change leading to preservation.

We thank J. Perkins (Perkins Farms) and D. Brown (Carlhaven Farms) for ostrich and emu specimens, respectively, and $\mathrm{T}$. Collier for assistance with collection and processing of specimens. Fossil specimens were provided by L. Brand (Loma Linda University), R. Coria (Museo Carmen Funes), M. Flynn (Sheridan College), C. A. Forster (State University of New York, Stonybrook), C. Hill (Boise State University), A. Kellner (National Museum of Rio de Janeiro), D. Krause (State University of New York, Stonybrook), University of Florida, P. Larson (Black Hills Institute), P. Mackovicky (Field Museum of Natural History), Aukland Science Center and V. Schneider (North Carolina State Museum of Natural Sciences). Electron microscopy imaging time was provided by R. Avci (ICAL, Montana State University), S. Brumfield (Montana State University) and M. Dykstra (LAELOM, College of Veterinary Medicine, North Carolina State University). We thank M. Franklin, C. Paden and J. Starkey (MSU) for visiting lab space, and N. Equall, E. Lamm and E. Swogger for technical assistance. Invaluable discussions, advice and editing were provided by: N. Blair, J. Fountain, N. Hinman, L. Leithold, D. Schwimmer and M. Tientze. Funding for this work was provided by National Science Foundation (EAR-0435626), Discovery Channel and North Carolina State University.

\section{REFERENCES}

Adams, J. S. \& Organ, C. 2005 Histologic determination of ontogenetic patterns and processes in hadrosaurian ossified tendons. F. Vert. Paleontol. 25, 614-622. (doi: 10. 1671/0272-4634(2005)025[0614:HDOOPA]2.0.CO;2)

Allison, P. A. 1988 The role of anoxia in the decay and mineralization of proteinaceous macro-fossils. Paleobiology 14, 139-154.

Ambler, R. P. \& Daniel, M. 1991 Proteins and molecular paleontology. Phil. Trans. R. Soc. B 333, 381-389.

Bada, J. L., Wang, X. Y. S. \& Hamilton, H. 1999 Preservation of key biomolecules in the fossil record: current knowledge and future challenges. Phil. Trans. R. Soc. B 354, 77-86. (doi:10.1098/rstb.1999.0361)

Behrensmeyer, A. K. \& Kidwell, S. M. 1985 Taphonomy's contributions to paleobiology. Paleobiology 11, 105-119.

Brand, L. 2003 Stratigraphy of the Miocene/Pliocene Pisco Formation in the Pisco basin. Peru. Geol. Soc. Amer. Abstr. with Programs 35, 160.

Brand, L. R., Esperante, R., Chadwick, A. V., Poma, O. \& Alomia, M. 2004 Fossil whale preservation implies high diatom accumulation rate in the Miocene-Pliocene Pisco Formation of Peru. Geology 32, 165-168. (doi: 10.1130/ G20079.1) 
Briggs, D. E. G. 2003 The role of decay and mineralization in the preservation of soft-bodied fossils. Ann. Rev. Earth Planet Sci. 31, 275-301. (doi: 10.1146/annurev.earth.31. 100901.144746)

Briggs, D. E. G. \& Kear, A. J. 1993 Fossilization of soft-tissue in the laboratory. Science 259, 1439-1442.

Briggs, D. E. G., Kear, A. J., Martill, D. M. \& Wilby, P. R. 1993 Phosphatization of soft-tissue in experiments and fossils. F. Geol. Soc. 150, 1035-1038.

Briggs, D. E. G., Evershed, R. P. \& Lockheart, M. J. 2000 The biomolecular paleontology of continental fossils. Paleobiology 26, 169-193.

Brochu, C. A. 2003 Osteology of Tyrannosaurus rex: insights from a nearly complete skeleton and high-resolution computed tomographic analysis of the skull. F. Vert. Paleontol. 22, S.

Butterfield, N. J. 1990 Organic preservation of nonmineralizing organisms and the taphonomy of the Burgess Shale. Paleobiology 16, 272-286.

Butterfield, N. J. 2003 Exceptional fossil preservation and the Cambrian explosion. Integr. Comp. Biol. 43, 166-177. (doi: 10.1093/icb/43.1.166)

Cohen, W. D. 1991 The cytoskeletal system of nucleated erythrocytes. Int. Rev. Cyt. 130, 37-84.

Collins, M. J., Waite, E. R. \& van Duin, A. C. T. 1999 Predicting protein decomposition: the case of aspartic acid racemization kinetics. Phil. Trans. R. Soc. B 354, 51-64. (doi: 10.1098/rstb.1999.0359)

Collins, M. J., Muyzer, G., Westbroek, P., Curry, G. B., Sandberg, P. A., Xu, S. J., Quinn, R. \& MacKinnon, D. 1991 Preservation of fossil biopolymeric structures: conclusive immunological evidence. Geochim. et Cosmochim. Acta 55, 2253-2257. (doi: 10.1016/0016-7037(91) 90101-A)

Collins, M. J., Bishop, A. N. \& Farrimond, P. 1995 Sorption by mineral surfaces: rebirth of the classical condensation pathway for kerogen formation? Geochem. et Cosmochim. Acta 59, 2387-2391. (doi: 10.1016/00167037(95)00114-F)

Collins, M. J., Gernaey, A. M., Nielsen-Marsh, C. M., Vermeer, C. \& Westbroek, P. 2000 Slow rates of degradation of osteocalcin: green light for fossil bone protein? Geology 28, 1139-1142. (doi: 10.1130/00917613(2000) $28<1139:$ SRODOO $>2.0$. CO;2)

Collins, M. J., Nielsen-Marsh, C. M., Hiller, J., Smith, C. I., Roberts, J. P., Prigodich, R. V., Wess, T. J., Csapò, J., Millard, A. R. \& Turner-Walker, G. 2002 The survival of organic matter in bone: a review. Archaeometry 44, 383-394. (doi:10.1111/1475-4754.t01-1-00071)

Corbett, J. \& Golan, D. E. 1993 Band 3 and glycophorin are progressively aggregated in density-fractionated sickle and normal red blood cells. Evidence from rotational and lateral mobility studies. F. Clin. Invest. 91, 208-217.

DeJong, E. W., Westbroek, P., Westbroek, J. F. \& Bruning, J. W. 1974 Preservation of antigenic properties of macromolecules over 70 Myr. Nature 252, 63-64. (doi: $10.1038 / 252063 \mathrm{a} 0$ )

Denys, C. 2002 Taphonomy and experimentation. Archaeometry 44, 469-484. (doi:10.1111/1475-4754.00079)

Eglinton, G. \& Logan, G. A. 1991 Molecular preservation. Phil. Trans. R. Soc. B 333, 315-328.

Erickson, G. M. 2005 Assessing dinosaur growth patterns: a microscopic revolution. Trends Ecol. Evol. 20, 677-684. (doi: 10.1016/j.tree.2005.08.012)

Erickson, G. M., Makovicky, P. J., Currie, P. J., Norell, M. A., Yerby, S. A. \& Brochu, C. A. 2004 Gigantism and comparative life-history parameters of tyrannosaurid dinosaurs. Nature 430, 772-775. (doi: 10.1038/nature02699)
Esperante, R. 2002 Taphonomy of fossil whales in diatomaceous sediments of the Neogene Pisco Formation, Peru. Ph.D. dissertation, Loma Linda University.

Esperante-Caamano, R., Brand, L., Chadwick, A. \& Poma, O. 2002 Taphonomy of fossil whales in the diatomaceous sediments of the Miocene/Pliocene Pisco Formation, Peru. In Current topics on taphonomy and fossilization (ed. M. DeRenzi, M. Alonso, M. Belinchon, E. Penalver, P. Montoya \& A. Marquez-Aliaga), pp. 337-343 Taphos Third Meeting on Taphonomy and Fossilization, Valencia, Spain February 14-16 2002. Valencia, Spain: Ayuntamiento de Valencia.

Ferris, F. G., Fyfe, W. S. \& Beveridge, T. J. 1988 Metallic ion binding by Bacillus subtilis: implications for the fossilization of micro-organisms. Geology 15, 149-152. (doi:10. 1130/0091-7613(1988)016<0149:MIBBBS > 2.3.CO;2)

Francis, S. E., Sullivan Jr, D. J. \& Goldberg, D. E. 1997 Hemoglobin metabolism in the malaria parasite Plasmodium falciparum. Ann. Rev. Microbiol. 51, 97-123. (doi: 10. 1146/annurev.micro.51.1.97)

Glimcher, M. J., Cohen-Solal, L., Kossiva, D. \& deRicqles, A. 1990 Biochemical analyses of fossil enamel and dentin. Paleobiology 16, 219-232.

Gotherstrom, A., Collins, M. J., Angerbjorn, A. \& Liden, K. 2002 Bone preservation and DNA amplification. Archaeometry 44, 395-404. (doi: 10.1111/1475-4754. 00072)

Green, J., Schneider, V., Schweitzer, M. H. \& Clarke, J. A. 2005 New evidence for non-Placerias dicynodonts in the Late Triassic (Carnian-Norian) of North America. f. Vert. Paleontol. 25, 65A.

Gutteridge, J. M. C., Rowley, D. A. \& Halliwell, B. 1981 Superoxide dependent formation of hydroxyl radicals in the presence of iron salts. Biochem. F. 199, 263-265.

Harmon, R. 1997 The excavation and recovery of an articulated adult Brachylophosaurus skeleton. F. Vert. Paleontol. 17, 51A.

Hedges, R. E. M. 2002 Bone diagenesis: an overview of process. Archaeometry 44, 319-328. (doi: 10.1111/14754754.00064)

Hill, C. L. 1998 American mastodon (Mammut americanum) from the Doeden Gravels, Number 2 Terrace, Lower Yellowstone River. In Am. Quat. Assn. Abst. 15th Biennial Meeting. Northern Hemisphere-Southern Hemisphere Interconnection. Puerto Vallarta, Mexico.

Hill, C. L. \& Schweitzer, M. H. 1999 Mammoth (Mammuthus) from the Doeden Gravels Eastern Montana: biometric and molecular analyses. Curr. Res. Pleist. 16, 120-123.

Hirschberg, R. M., Mulling, C. K. W. \& Bragulla, H. 1999 Microvasculature of the bonvine claw demonstrated by improved micro-corrosion-casting technique. Microsc. Res. Tech. 45, 184-197. (doi:10.1002/(SICI) 1097-0029 (19990501)45:3 < 184::AID-JEMT6 > 3.0.CO;2-O)

Horner, J. R. \& Padian, K. 2004 Age and growth dynamics of Tyrannosaurus rex. Proc. $R$. Soc. B 271, 1875-1880. (doi: 10.1098/rspb.2004.2829)

Hoss, M. 2000 Neanderthal population genetics. Nature 404, 453-454. (doi: 10.1038/35006551)

Hubert, B., Alvaro, J. J. \& Chen, J.-Y. 2005 Microbially mediated phosphatization in the Neoproterozoic Doushantuo Lagerstatte. South China Bull. Soc. Geol. Fr. 176, 355-361.

Jans, M. M. E., Nielsen-Marsh, C. M., Smith, C. I., Collins, M. J. \& Kars, H. 2004 Characterisation of microbial attack on archaeological bone. F. Arch. Sci. 31, 87-95. (doi: 10. 1016/j.jas.2003.07.007)

Kellner, A. W. A. 1996 Fossilized theropod soft tissue. Nature 379, 32. (doi: 10.1038/379032a0) 
Lee, J.-U \& Fein, J. B. 2000 Experimental study of the effects of Bacillus subtilis on gibbsite dissolution rates under nearneutral $\mathrm{pH}$ and nutrient-poor conditions. Chem. Geol. 166, 193-202. (doi: 10.1016/S0009-2541(99)00191-6)

Lee-Thorp, J. 2002 Two decades of progress towards understanding fossilization processes and isotopic signals in calcified tissue minerals. Archaeometry 44, 435-446. (doi: 10.1111/1475-4754.t01-1-00076)

Lindahl, T. 1993 Recovery of antediluvian DNA. Nature 365, 700. (doi: 10.1038/365700a)

Maat, G. J. R. 1991 Ultrastructure of normal and pathological fossilized red blood cells compared with pseudopathological biological structures. Int. f. Osteoarch. 1, 209-214. (doi: 10.1002/oa.1390010312)

Maat, G. J. R. 1993 Bone preservation, decay and its related conditions in ancient human bones from Kuwait. Int. f. Osteoarch. 3, 77-86. (doi: 10.1002/oa.1390030204)

MacNamera, M. E., Orr, P. J., Kearns, S. L., Alcala, L., Anadon, P. \& Penalver-Molla, E. 2006 High-fidelity organic preservation of bone marrow in ca $10 \mathrm{Ma}$ amphibians. Geology 34, 641-644. (doi: 10.11310/ G22526.1)

Mann, S., Davis, S. A., Hall, S. R., Li, M., Rhodes, K. H., Shenton, W., Vaucher, S. \& Zhang, B. 2000 Crystal tectonics: chemical construction and self-organization beyond the unit cell. F. Chem. Soc. Dalton Trans. 2000, 3753-3763. (doi: 10.1039/b004066p)

Martill, D. M. 1990 Macromolecular resolution of fossilized muscle tissue from an elopomorph fish. Nature 346, 171-172. (doi: 10.1038/346171a0)

Martill, D. M. 1994 Instantaneous fossilization. Recherché 25, 996-1002.

Martill, D. M. \& Unwin, D. M. 1997 Small spheres in fossil bones: blood corpuscles or diagenetic products? Palaeontology 40, 619-624.

Mladenka, P., Simunek, T., Hubl, M. \& Hrdina, R. 2006 The role of reactive oxygen and nitrogen species in cellular iron metabolism. Free Rad. Res. 40, 263-272. (doi: 10.1080/ $10715760500511484)$

Nguyen, R. T. \& Harvey, H. R. 2001 Preservation of protein in marine systems: hydrophobic and other noncovalent associations as major stabilizing forces. Geochim. et Cosmochim. Acta 65, 1467-1480. (doi:10.1016/S00167037(00)00621-9)

Nikinmaa, M. 1990 Vertebrate red blood cells, p. 262. Berlin, Germany: Springer.

Pawlicki, R. 1995 Histochemical demonstration of DNA in osteocytes from dinosaur bones. Folia Histochem. et Cytochem. 33, 183-186.

Pawlicki, R. \& Nowogrodzka-Zagorska, M. 1998 Blood vessels and red blood cells preserved in dinosaur bone. Ann. Anat. 180, 73-77.

Pawlicki, R., Korbel, A. \& Kubiak, H. 1966 Cells, collagen fibrils and vessels in dinosaur bone. Nature 211, 656. (doi: $10.1038 / 211655 \mathrm{a} 0)$

Prieto, J. L., Magana, C. \& Ubelaker, D. H. 2004 Interpretation of postmortem changes in cadavers in Spain. F. Forensic Sci. 49, 918-923. (doi:10.1520/ JFS2003337)

Prieto-Marquez, A. $2005 \mathrm{New}$ information on the cranium of Brachylophosaurus canadensis (Dinosauria, Hadrosauridae), with a revision of its phylogenetic position. F. Vert. Paleontol. 25, 144-156. (doi: 10.1671/0272-4634(2005) 025[0144:NIOTCO]2.0.CO;2)

Rank, B. H., Carlsson, J. \& Hebbel, R. P. 1985 Abnormal redox status of membrane-protein thiols in sickle $\mathrm{Y}$ erythrocytes. F. Clin. Invest. 75, 1531-1537.

Riley, M. S. \& Collins, M. J. 1994 The polymer model of collagen degradation. Polym. Degrad. Stab. 46, 93-97. (doi:10.1016/0141-3910(94)90113-9)
Rogers, R. R. 2005 Fine-grained debris flows and extraordinary vertebrate burials in the Late Cretaceous of Madagascar. Geology 33, 297-300. (doi: 10.1130/ G21036.1)

Rogers, R. R., Hartman, J. H. \& Krause, D. W. 2000 Stratigraphic analysis of Upper Cretaceous rocks in the Mahajanga Basin, northwestern Madagascar: implications for ancient and modern faunas. F. Geology 108, 275-301. (doi: 10.1086/314403)

Salamon, M., Tuross, N., Arensburg, B. \& Weiner, S. 2005 Relatively well preserved DNA is preserved in the crystal aggregates of fossil bones. Proc. Natl Acad. Sci. USA 102, 13 783-13 788. (doi: 10.1073/pnas.0503718102)

Schafer, F. Q., Yue Qian, S. \& Buettner, G. R. 2000 Iron and free radical oxidations in cell membranes. Cell. Mol. Biol. 46, 657-662.

Schmidt-Schultz, T. \& Schultz, M. 2004 Bone protects proteins over thousands of years: extraction, analysis and interpretation of extracellular matrix proteins in archeological skeletal remains. Am. F. Phys. Anthro. 123, 30-39. (doi: 10.1002/ajpa.10308)

Schopf, J. W. 1975 Precambrian paleobiology-problems and perspectives. Annu. Rev. Earth Planet. Sci. 3, 213-249. (doi: 10.1146/annurev.ea.03.050175.001241)

Schweitzer, M. H. \& Horner, J. R. 1999 Intravascular microstructures in trabecular bone tissues of Tyrannosaurus rex. Ann. Paleontol. 85, 179-192. (doi: 10.1016/ S0753-3969(99)80013-5)

Schweitzer, M. H., Marshall, M., Carron, K., Bohle, D. S., Busse, S., Arnold, E., Johnson, C. \& Starkey, J. R. 1997 a Heme compounds in dinosaur trabecular tissues. Proc. Natl Acad. Sci. USA 94, 6291-6296. (doi:10.1073/pnas. 94.12.6291)

Schweitzer, M. H., Johnson, C., Zocco, T. G., Horner, J. R. \& Starkey, J. R. $1997 b$ Preservation of biomolecules in cancellous bone of Tyrannosaurus rex. F. Vert. Paleontol. 17, 349-359.

Schweitzer, M. H., Watt, J. A., Avci, R., Knapp, L., Chiappe, L., Norell, M. \& Marshall, M. 1999a Betakeratin specific immunological reactivity in feather-like structures of the Cretaceous Alvarezsaurid, Shuvunia deserti. F. Exp. Zool. (Mol. Dev. Evol.) 285, 146-157. (doi: 10.1002/(SICI) 1097-010X(19990815)285:2<146:: AID-JEZ7>3.0.CO;2-A)

Schweitzer, M. H., Watt, J. A., Avci, R., Forster, C. A., Krause, D. W., Knapp, L., Rogers, R., Beech, I. \& Marshall, M. $1999 b$ Keratin-specific immunoreactivity in claw sheath material from a late Cretaceous bird from Madagascar. F. Vert. Paleontol. 19, 712-722.

Schweitzer, M. H., Hill, C. L., Asara, J. M., Lane, W. S. \& Pincus, S. H. 2002 Identification of immunoreactive material in mammoth fossils. F. Mol. Evol. 55, 696-705. (doi: 10.1007/s00239-002-2365-6)

Schweitzer, M. H., Wittmeyer, J. L., Horner, J. R. \& Toporski, J. B. 2005 a Soft tissue vessels and cellular preservation in Tyrannosaurus rex. Science 307, 1952-1955. (doi: 10.1126/science.1108397)

Schweitzer, M. H., Wittmeyer, J. L. \& Horner, J. R. $2005 b$ Gender-specific reproductive tissue in ratites and Tyrannosaurus rex. Science 308, 1456-1460. (doi: 10.1126/ science.1112158)

Smith, C. I., Craig, O. E., Prigodich, R. V., Nielsen-Marsh, C. M., Jans, M. M. E., Vermeer, C. \& Collins, M. J. 2005 Diagenesis and survival of osteocalcin in archaeological bone. F. Arch. Sci. 32, 105-113. (doi:10.1016/j.jas.2004. 07.003)

Stankiewicz, B. A., Briggs, D. E. G., Michels, R., Collinson, M. E., Flannery, M. B. \& Evershed, R. P. 2000 Alternative 
origin of aliphatic polymer in kerogen. Geology 28, 559-562. (doi: 10.1130/0091-7613(2000) $28<559$ : AOOAPI > 2.0.CO;2)

Sykes, G. A., Collins, M. J. \& Walton, D. I. 1995 The significance of a geochemically isolated intracrystalline organic fraction within biominerals. Org. Geochem. 23, 1059-1065. (doi:10.1016/0146-6380(95)00086-0)

Tibbett, M. A., Carter, D. O., Haslam, T., Major, R. \& Haslam, R. 2004 A laboratory incubation method for determining the rate of microbiological degradation of skeletal muscle tissue in soils. F. Forensic Sci. 49, 560-565. (doi: 10.1520/JFS2003247)

Tissot, B. P. \& Welte, D. H. 1984 Petroleum formation and occurrence, p. 699. Berlin, Germany: Springer.

Towe, K. W. 1980 Preserved organic ultrastructure: an unreliable indicator for Paleozoic amino acid biogeochemistry. In Biogeochemistry of amino acids (ed. P. E. Hare, T. C. Hoering \& K. King), pp. 65-73. New York, NY: Wiley.

Trepel, M., Arap, W. \& Pasqualini, R. 2002 In vivo phage display and vascular heterogeneity: implications for targeted medicine. Curr. Opin. Chem. Biol. 6, 399-404. (doi:10.1016/S1367-5931(02)00336-8)

Trueman, C. N. \& Martill, D. M. 2002 The long-term survival of bone: the role of bioerosion. Archaeometry 44, 371-382. (doi: 10.1111/1475-4754.t01-1-00070)

Tuross, N. 2002 Alterations in fossil collagen. Archaeometry 44, 427-434. (doi:10.1111/1475-4754.00075)

Usui, Y., Kawai, K. \& Hirohata, K. 1989 An electron microscopic study of the changes observed in osteocytes under ischemic conditions. F. Orth. Res. 7, 12-21. (doi: 10. 1002/jor.1100070103)

Vass, A. A., Barshick, S. A., Sega, G., Caton, J., Skeen, J. T., Love, J. C. \& Synstelien, J. A. 2002 Decomposition chemistry of human remains: a new methodology for determining the postmortem interval. F. Forensic Sci. 47, 542-553.
Weiner, S. \& Traub, W. 1989 Crystal size and organization in bone. Connect. Tiss. Res. 21, 589-595.

Weiner, S., Traub, W. \& Elster, H. 1989 The molecular structure of bone and its relation to diagenesis. Appl. Geochem. 4, 231-232. (doi:10.1016/0883-2927(89) 90022-X)

Weiner, S., Goldberg, P. \& Bar-Yosef, O. 1993 Bone preservation in Kebara Cave, Israel, using on-site Fourier transform infrared spectrometery. f. Arch. Sci. 20, 613-617. (doi: 10.1006/jasc.1993.1037)

Weiner, S., Traub, W. \& Wagner, H. D. 1999 Lamellar bone: structure-function relations. F. Struct. Biol. 126, 241-255. (doi: 10.1006/jsbi.1999.4107)

Wightman, P. G. \& Fein, J. B. 2005 Iron adsorption by Bacillus subtilis bacterial cell walls. Chem. Geol. 216, 177-189. (doi: 10.1016/j.chemgeo.2004.11.008)

Wilby, P. R. 1993 The role of organic matrices in postmortem phosphatization of soft tissues. Kaupia 2, 99-113.

Wilby, P. R. \& Whyte, M. A. 1995 Phosphatized tissues in bivalves from the Portland Roach of Dorset, (Upper Jurassic). Geol. Mag. 132, 117-120.

Wilby, P. R., Briggs, D. E. G., Bernier, P. \& Gaillard, C. 1996 Role of microbial mats in the fossilization of soft tissues. Geology 24, 787-790. (doi:10.1130/0091-7613(1996)024 $<0787$ :ROMMIT > 2.3.CO;2)

Wilson, L. \& Pollard, A. M. 2002 Here today, gone tomorrow? Integrated experimentation and geochemical modeling in studies of archaeological diagenetic change. Acc. Chem. Res. 35, 644-651. (doi: 10.1021/ar000203s)

Zhu, M., Babckock, L. E. \& Steiner, M. 2005 Fossilization modes in the Chengiiang Lagerstatte (Cambrian of China): testing the roles of organic preservation and diagenetic alteration in exceptional preservation. Palaeogeo. Palaeoclim. Palaeoecol. 220, 31-46. (doi:10.1016/ j.palaeo.2003.03.001) 